\title{
Quiste de la hendidura branquial en paciente anciano: un reto diagnóstico
}

\section{Branchial cleft cyst in an aged patient: a challenging differential diagnosis}

A 70-year-old male patient, with a medical history of stable multinodular goiter, was referred to the endocrinology consultation by nodular growth. Thyroid ultrasound showed a well-defined anechoic lesion in the right lobe with $30 \mathrm{~mm}$ at its largest diameter (longitudinal axis), and other micronodular structures of unsuspected malignancy (figure 1).

The patient presented no altered thyroid function (Thyroid-Stimulating Hormone [TSH] $1.28 \mu \mathrm{Ul} / \mathrm{mL}$ [0.27-4.2]; free T4 $1.08 \mathrm{ng} / \mathrm{mL}$ [0.93-1.70]). Fine needle aspiration biopsy of the identified lesion was performed. A yellow and thick fluid was instantly visualized. Cytological examination evidenced superficial squamous cells without atypia, follicular cells and colloid fluid, favouring extrathyroidal origin. Cervical Computed Tomography (CT) was carried out, due to compressive symptoms (dysphagia and dyspnea).

It unveiled an ovoid intrathyroidal lesion, causing moderate prominence of the right thyroid lobe and contralateral tracheal shift (figure 2). Right hemithyroidectomy was performed without any complications. Extemporaneous intraoperative macroscopic examination denoted a thin-walled, cystic lesion with a smooth inner surface. The corresponding histopathological examination of the surgical specimen revealed a cystic wall covered by stratified pavement epithelium, consistent with a branchial cleft cyst (figures $3 \mathrm{~A}$ and 3B). Compressive symptoms disappeared after surgery. Currently, the patient remains under 6-month follow-up with thyroid function tests and ultrasonographic reassessment.

Branchial cleft cysts are derived from the incomplete obliteration of branchial cleft apparatus that lasts after embryonic development. They are usually placed in the lateral cervical areas, representing a great proportion of the neck congenital anomalies ${ }^{1}$. However, this case shows an intrathyroidal branchial cleft cyst, an extremely rare location, whose pathophysiology remains uncertain. It has been postulated that intrathyroidal cysts may develop from the failure to atrophy of the third or fourth branchial pouches, ending up closely, or inside, the thyroid gland2. Malignancy should be presumed and excluded as neck cancers may present as cystic masses, especially concerning atypically located neck masses emerging in adulthood ${ }^{3}$. Hence, the diagnosis was confirmed only after histopathological analysis.

The present case is singular, due to the rarity of its initial presentation in adulthood, and its unusual intrathyroidal location. For this reason, the authors consider crucial a high level of suspicion, regarding the broad differential diagnosis of cervical masses, as other more frequent and well-known congenital anomalies (e.g., thyroglossal duct cyst).

\section{REFERENCES}

1. Adams A, Mankad K, Offiah C, Childs L. Branchial cleft anomalies: a pictorial review of embryological development and spectrum of imaging findings. Insights Imaging. 2016;7(1):69-76.

2. Liberman M, Kay S, Emil S, Flageole H, Nguyen LT, Tewfik TL, et al. Ten years of experience with third and fourth branchial remnants. J Pediatr Surg. 2002;37(5):685-90.

3. Pynnonen MA, Gillespie MB, Roman B, Rosenfeld RM, Tunkel DE, Bontempo L, et al. Clinical Practice Guideline: Evaluation of the Neck Mass in Adults Executive Summary. Otolaryngol Head Neck Surg. 2017;157(3):355-71.

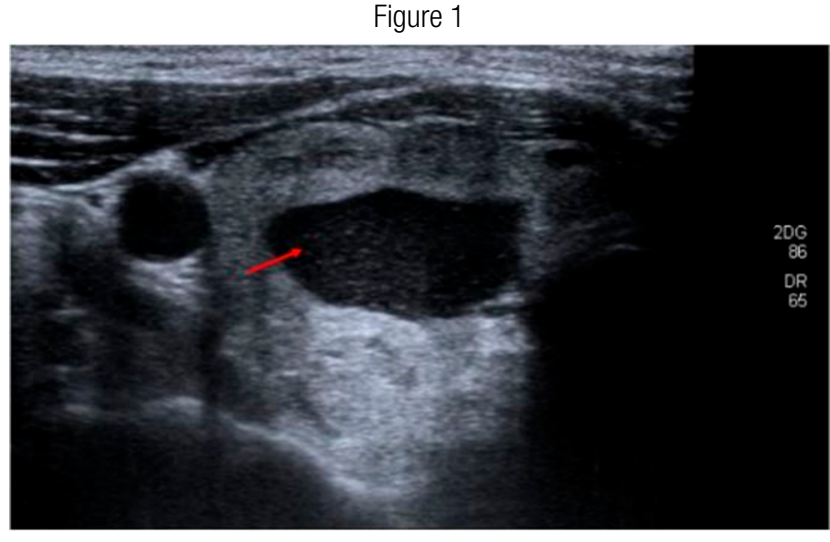

Figure 2

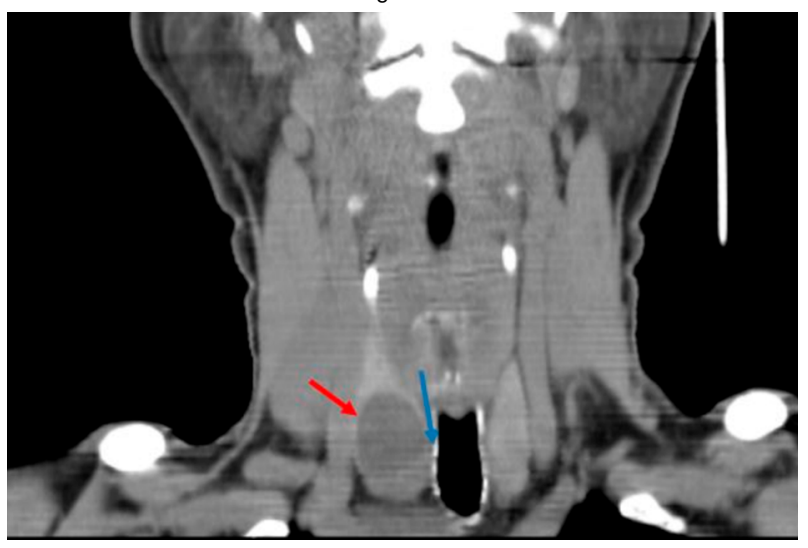

Figure $3 \mathrm{~A}$

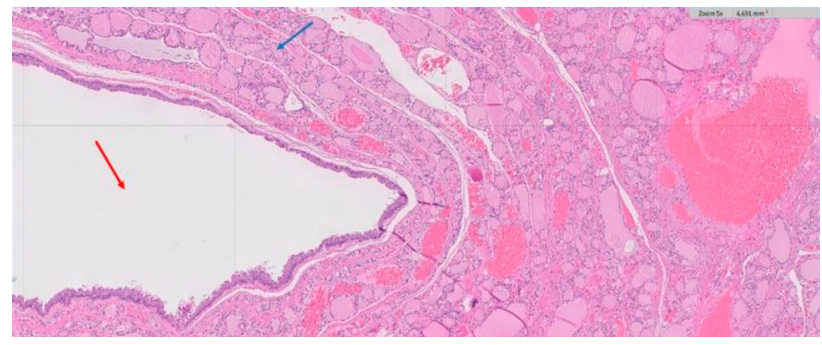

Figure 3B

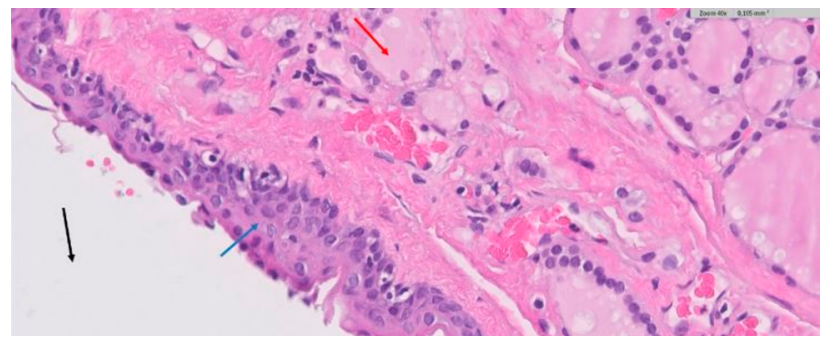

Diogo Ramalho, Gustavo Rocha

Centro Hospitalar de Vila Nova de Gaia / Espinho

Correspondencia: silva.josediogo@gmail.com

Cómo citar este artículo: Ramalho D, Rocha $G$

Branchial cleft cyst in an aged patient: a challenging differential diagnosis. Galicia Clin 2021; 82-3: 174

Recibido: 15/06/2020; Aceptado: 09/03/2021 // https://doi.org/10.22546/62/2336 